\title{
Who Cares?
}

\section{-The COVID-19 Pandemic, Global Heating and the Future of Humanity}

\section{Torbjörn Tännsjö}

Stockholm University; torbjorn.tannsjo@philosophy.su.se

Submitted: 27 April 2020, accepted: 11 December 2020, published: 25 April 2021

\begin{abstract}
The COVID-19 pandemic has engendered unprecedented drastic and costly measures to obviate the threat. Will something similar happen in relation to global heating? No, this is not likely. Mainly this has to do with a difference in the nature of collective action. Nation states protect their respective populations against the virus. With regard to global heating, we are facing the tragedy of the commons. No global government assumes responsibility for our common future. However, there may be another and further explanation lurking behind political inaction: many people, including our politicians, think that it does not matter if humanity goes extinct. It does matter, however. Strangely enough, the view that it matters is questioned by many important philosophers in the past and in the present, and it is hence controversial. Yet, it should be our common-sense stance to the problem. It is of the utmost importance that there will be sentient happy life on the globe for an indefinite time. Theoretically speaking, in order to recognize this, we need to accept some "total" view, implying what has been called the repugnant conclusion. Practically speaking, we should go to great length to rescue our human civilisation, even if this means that, for a while, we must endure all sorts of hardships such as a global enlightened despotism, or worse-a situation of life boat ethics.
\end{abstract}

Keywords: global heating; global government; global despotism; life-boat ethics; pessimism; actualism; deep ecology; the repugnant conclusion

How to cite: Tännsjö, T. Who Cares? Journal of Controversial Ideas 2021, 1(1), 1; doi:10.35995/jci01010001.

(C) 2021 Copyright by the author. This article is an open access article distributed under the terms and conditions of the Creative Commons Attribution (CC BY 4.0) license.

(c) (i)

\section{Introduction}

Global heating threatens to kill off human civilization and perhaps, in turn, the human race. The United Nations Climate Change Conference in Madrid was yet another disappointment. The prospects for the Glasgow summit are also bleak. Now, the meeting

\footnotetext{
1 I thank Jens Johansson and an anonymous reviewer for the journal for helpful and constructive comments on an earlier draft of this paper.
} 
has been postponed until November 2021 and, in the wake of the COVID-19 crisis, new problems mount. It is true that the present pandemic will reduce emissions. It is true that the present corona crisis has demonstrated that national governments are prepared to take drastic and costly measures to protect their respective populations. Does this show that the same governments will be prepared to take drastic and costly measures to obviate the threat from global heating? The answer is no. As soon as the present pandemic crisis is over all sorts of efforts will be made to get the industrial wheels turning again. This has to do with a structural difference in collective decision making. With regard to the pandemic the structure of the decision problem is simple, egoistic and straightforward. Each government tends to its "own" population. With regard to global heating the structure of the decision problem is different: here, we are faced with a decision problem named in 1968 by the American ecologist Garrett Hardin "the tragedy of the commons". ${ }^{2}$ It shares an important characteristic with a well-known (at least since the 1950s) ${ }^{3}$ problem, the prisoner's dilemma: if all actors respectively in the game succeed in seeing to their own best interests, they all end up in a sub-optimal outcome. Here is how the tragedy of the commons manifests itself in relation to global heating.

A well-tempered globe is a common good. Regardless of whether an individual (nation) has contributed to the creation of the good, the good is there, free for everyone to enjoy. We can all reap the fruits of a sustainable environment. Additionally, our individual (even national) contributions to the destruction of the good through emissions of greenhouse gases do not harm us in any noticeable manner. We only suffer from what we all do together. Individually, we think it is fine of others contribute to the solution, but, regardless of what they do, we stand to gain from ourselves abstaining.

It might be objected that the climate crisis presents us with an instance of the tragedy of the commons only if we consider what each individual nation can do to cut its own omissions. However, what if a wealthy nation such as the USA assumes responsibility for the entire globe, not out of concern for others, but in its own best interest? I owe the objection to an anonymous reviewer for the journal who puts it like this:

Suppose Biden is elected and the US spends trillions of dollars contributing to solving global heating. Suppose the US gets only one hundredth the global benefit of this spending and that other countries get the benefit for free. It may still be worth it just in terms of current and future generations of Americans for the US to spend all this money.

This reference to Biden made sense at the time of writing, but readers and the present writer now know that Biden was capable of defeating Trump. However, regardless of who won the election in November 2020, and how this was done, we can speculate about this possible scenario. It is hardly less likely that Trump would be prepared to save America, even if the means to this end would be to save humanity as such, than it is to assume that this is something Biden will do. Both scenarios are highly unlikely. However, theoretically speaking, this objection makes good sense. Additionally, since we are facing an existential risk (or even doom for certain), if we can obviate it, any monetary price seems to be worth paying to this effect. From a practical point of view, I think we can safely ignore this scenario, however. This is partly because it is so extremely unrealistic that any American president would embark on such a policy, but also, and more importantly, because it is

2 Garrett Hardin, 'The Tragedy of the Commons,' Science New Series 162 (1968): 1243-8.

3 It is commonly attributed to A.W. Tucker. 
unlikely that it is possible for an American president to achieve what is described in the objection. This is not a feasible option for him, and there is no sign even of Biden trying to opt for such a policy.

The way of best implementing the policy would be to keep the US industries relying on fossil material, hence continuing with the US greenhouse emissions (since they have only a marginal impact on the Americans), while bailing out the fossil businesses elsewhere in the world. I am no expert on economy and cannot tell whether this would be economically possible. If I am right in what I claim below, i.e., that we need an immediate stop for greenhouse emissions, then it would be terribly costly. It would certainly require extremely heavy taxes at home, but also an unprecedented compliant attitude overseas. The Americans must be prepared to pay for it and national governments such as the Chinese Communist Party would have to allow the US to buy and close down companies in their respective territories. Furthermore, states themselves exploiting oil such as Saudi Arabia and Venezuela must be prepared to stop doing so in exchange for US dollars. I think we confidently assume that this will not happen. Even if governments all over the globe would gladly accept the offered US dollars, there is no guarantee that they will honour the agreement to close done their fossil industries or avoid opening up new ones. Therefore, some kind of US surveillance and a system of sanctions would be needed in tandem with the flow of US dollars. However, we are now approaching a situation where the USA conquers the world and establishes a new political world order. There may have existed a situation where this was possible, such as when the West enjoyed a monopoly on nuclear weapons. Bertrand Russell famously argued that the West should seize this possibility. ${ }^{4}$ When the Soviet Union developed their own nukes, this window of opportunity closed down. Additionally, the idea that the USA could buy the rest of the world makes little sense. Even Trump's offer to buy Greenland was met with suspicion. I will return, however, to the idea of a new global political order, established in a different way.

There is another complication in relation to global heating, absent from the dealing with the COVID-19 pandemic. The economic effects of government action in relation to this pandemic are indirect. They result from a policy of social distancing. As a matter of fact, they are there, irrespective of whether the restrictions on individual freedom take the form of legal prescriptions or mere good advice. Even in a country like Sweden, where the main strategy against the pandemic has been advice rather than legal sanctions, people have voluntarily and in their own perceived best interest complied with the recommendations from the authorities. As an indirect consequence, the economy has been hurt. The actions in relation to global heating must by directly targeted against bug business in general and fossil business, in particular, closing down activities that result in greenhouse emissions. The opposition from big economic interests is likely to be more powerful than the opposition has been from people at large in relation restrictions of individual freedom necessitated by the COVID-19 pandemic; the latter realising that they have had their individual freedom restricted in their own best interest. The former having their economic freedom restricted in the interest of others.

Is there no solution to the problem posed by global heating? Perhaps a global state can deal with it, forcing individual states to carry their fair share of the sacrifices needed for

4 On November 20, 1948, in a public speech. The exact details about what he said are, however, contested. Nicholas Griffin of McMaster University, in The Selected Letters of Bertrand Russell: The Public Years, 1914-1970, Vol. 2 (Routledge, 2002), has claimed that Russell's wording implies he did not advocate the actual use of the atom bomb, but merely its diplomatic use as a massive source of leverage over the actions of the Soviets. 
a solution to the problem. Such a state could solve the tragedy of the commons problem on a global scale in analogy with how they have been solved in nation states. Additionally, it certainly takes a mighty global state to counter the economic interests opposing its policy. This is so, since it is unlikely that we will meet with an unheard-of readiness to make individual sacrifices in the interest of us all together. It is unlikely that individual states with take necessary action in the interest of the global population. It of note also that they lack many of the necessary resources for this, because of global (transnational) ownership of the means of production all over the world.

If this assessment is too pessimistic we will soon know this. We know it at the same time that China, Russia, Saudi Arabia, Brazil, the US, the EU, Norway and other nations promptly and jointly decide and manage to put down their coal mines and to close their oil taps. My conjecture is that this will not happen in time. Additionally, if climate science is correct, little time remains. It would have been highly beneficial if we had already established a global democracy. Many thinkers such as A.C. Ewing, Bertrand Russell, Albert Einstein and, without comparison, myself, have long argued that we should do this. ${ }^{5}$ However, we have not. Additionally, it is difficult to believe that a global democratic government is likely to emerge in time. We are steering steadily towards extinction. Or, at best, we must place our hope in some kind of global despotism emerging as a deus ex machina from some existing global organisation, just before time is up. This is the event in which I put my utmost hope. ${ }^{6}$ It may fail, however. Here, then, exists an even nastier possibility presented by what has been called "life boat ethics". I will return to it, but I start with what I see as a preferable: global despotism.

However, not everyone is as fond of the idea of global government as I am. There exists a tradition dating from Immanuel Kant ${ }^{7}$ to John Rawls ${ }^{8}$ and, most recently, Toby Ord, arguing that global government is undesirable in its own right and, in particular, problematic with regard to existential risks. One of the main concerns has been exactly this: it is likely that a global political order develops into a global despotism. This is how Kant puts the point, granting that we need cooperation on a global level (a law of nations) to obviate war, but warning against the idea of the merging of all the states into one:

The idea of a law of nations presupposes the separate existence of many states which are independent of each other. Such a situation constitutes in and by itself a state of war (unless there is a federal union to prevent hostilities breaking out). Yet such a situation is from the standpoint of reason better than the complete merging of all these states in one ... because the laws lose more and more of their effectiveness as the government increases in size, and the resulting soulless despotism is plunged into anarchy after having exterminated all the germs of good. ${ }^{9}$

5 For references, see Torbjörn Tännsjö, Global Democracy. The Case for a World Government (Edinburgh: Edinburgh University Press, 2008).

6 This is the topic of Torbjörn Tännsjö, 'Global Democracy and the Resort to Despotism: Global Democracy Revisited,' Philosophical Papers 48 (2019), OP: https://www.google.com/search?client=safarirls=enq=t\% C3\%A4nnsj\%C3\%B6+global+despotismie=UTF-8oe=UTF-8.

7 Immanuel Kant, Perpetual Peace and Other Essays, translated by Ted Humphrey (Indianapolis: Hacket Publishing Company, 1983).

8 John Rawls, The Law of Peoples (Cambridge Mass.: Harvard University Press, 1999).

9 Kant, Perpetual Peace, ibid., 259. 
Additionally, here is a recent quote from Toby Ord, in his book on existential risks:

... a politically homogenized world with a single point of control (roughly, the world as one big country) ... could increase overall existential risk via global totalitarianism, or by permanently locking in bad values. ${ }^{10}$

What, then, if global despotism (if perhaps not a soulless one) is what we need in order to survive the climate crisis? What if we have to make all kinds of sacrifices in the short run, sacrifices in terms of political freedom and economic prosperity, if we want to save humanity from global heating? Does this mean that we may just as well go under?

Our future looks gloomy. Is there a chance that we will survive? If we do, are the means necessary to ascertain our continued existence so terrible that we are prepared rather to let go? Would the cure be worse than the illness?

There is no lack of ideas of how to replace fossil fuels with other kinds of energy. However, such "green deals" take a lot of time to implement, and many of them create further emissions before they result in reductions. The truth is that the first action for a global government to take is to leave the carbon in the ground. This is what a world government must achieve immediately. When this has been accomplished, there is time for all sorts of creative inventions. However, such a timely stop of the emissions is bound to be extremely costly and burdensome. Big business will protest, and ordinary people will be reluctant to carry the indirect costs in terms of unemployment and a drastic cut in their consumption. The global government must be prepared to face the economic interests upfront and to cope with popular opposition. Is this feasible? Even if it is, is it desirable? Such bleak prospects for the human race invite the question: Does it matter of we all go extinct?

I focus here on the threat from global heating. There are of course other much-discussed existential risks, and I do not want to claim that the climate crisis is worse than threats, such as those posed by nuclear war and risks associated with Artificial Intelligence. However, this paper is about global heating and not about the other risks, and many of the arguments here presented generalize to other threats as well. Furthermore, the climate crisis is also special in one important regard. Given that the need to stop the emissions is of such emergency, given that it has to happen sooner rather than later, the momentary costs for averting the threat are enormous. This is my main reason for focusing on it.

It may seem that only a fool could claim that it does not matter if we go extinct. Those to whom it matters the most recently (before the pandemic outbreak) took to the streets or joined Greta Thunberg in her climate strike. However, there is a strong tradition within Western philosophy arguing that, given our human predicament, the coming to an end of humanity is morally unobjectionable or even desirable. If we simplify, we can discern three lines of argument in defence of this stance. Moreover, the defence of the view that it does matter if we go extinct is fraught with theoretical difficulties.

Therefore, what are we to say to those who do not give a damn? In particular, what are we to say to those who prefer destruction to global despotism?

This is a partly neglected question in the recent discussion on "existential" risks. Here, we read a lot about probabilities. How probable is it that, for one reason or another, we humans will go extinct? However, that is only part of the question. The other part concerns value. If we do go extinct, so what? What values are at stake?

10 Toby Ord, The Precipice. Existential Risk and The Future of Humanity (New York: Hachette, 2020), 202. 
We need to confront that question now. Additionally, many influential thinkers have claimed that nothing at all is at stake when we consider existential risks.

\section{Three Arguments in Defence of Indifference}

First of all, among them who do not give a damn, we have the outright pessimists. Life is not worth living, they hold. Or, even stronger, life is worth not living, i.e., it is better to be dead than to be alive.

The tradition started out with Socrates facing death and arguing (in his Defence) that death is no big deal. Not even the king of Persia ever experiences a day happier than a night of dreamless sleep.

Socrates inaugurated a tradition where thinkers such as Schopenhauer, and, in our own time, the South African philosopher David Benatar, ${ }^{11}$ have followed suit. Schopenhauer argued from a frustrationist stance-it is bad to have a preference frustrated but it of no positive value to have one satisfied-to the effect that life is at most not worth living. The German philosopher Christof Fehige ${ }^{12}$ has more recently defended this view. One single frustration means that a life is worth not living. One can here think of an analogous hedonistic view, according to which unhappiness matter morally speaking while happiness carries not moral weight (negative utilitarianism). This is not a popular view among hedonists (even if Benatar comes close to it). However, many philosophers of a hedonistic bent have supported the empirical claim that all the pain in the world outweighs all the happiness. The same is true of a typical human life. It contains more unhappiness than happiness. Hence, it would have been better not to have been born.

A similar claim can be made of course by a preferentialist. Even if the satisfaction of preferences is good and the frustration of them is bad, there may exist more frustration than satisfaction in the world.

In addition, there exists a special form of pessimism, even more radical than the one just mentioned. Here, we meet with thinkers who admit that a typical human life may contain more happiness than unhappiness. Yet, for all that, it had been better for these people not to be around. The reason is that unhappiness carries a special moral weight. The late Oxford philosopher Derek Parfit has dubbed a view to this effect "prioritarianism." ${ }^{13}$ According to prioritarianism, happiness has a kind of diminishing marginal moral importance; with unhappiness, it is the other way around.

On this view, if it is applied to moments rather than entire lives (the most plausible interpretation it seems to me), a life with ups and downs containing a net surplus of happiness over unhappiness may be worth not living because of the extra importance attaching to its downs. Morally speaking, the downs count for more than the ups. Their moral value, as it were, is larger than their nominal (hedonistic) value. Additionally, typically, a human life contains enough unhappiness to warrant the conclusion that it is on the whole worth not living. ${ }^{14}$

11 David Benatar, Better Never to Have Been: The Harm of Coming into Existence (Oxford: UP, 2008).

12 Christoph Fehige. 'A Pareto Principle of Possible People,' in Preferences, eds. Christoph Fehige and Ulla Wessels (Berlin: Walter de Gruyter, 1998).

13 Derek Parfit, 'Equality and priority,' Ratio 10 (1997): 202-21. OA: https://onlinelibrary.wiley.com/doi/abs/ 10.1111/1467-9329.00041.

14 I discuss this aspect of prioritarianism in Torbjörn Tännsjö, 'Utilitarianism or Prioritarianism,' Utilitas 27 (2015): OA: https://www.researchgate.net/publication/273528987_Utilitarianism_or_Prioritarianism. 
Secondly, apart from the pessimists, we have those who claim that morality is a matter of how we existing (actual) people relate to one another. There are things we ought to do, such as helping each other in distress, and there are things we are not allowed to do, such as killing one another. However, we have no obligation to cause individuals to exist. Even if at a certain time I could create a happy individual but do not, I make no moral mistake. I have no moral obligation towards a merely hypothetical person. I have negative obligations, though. If I create an individual for whom death is better than being alive my action is wrong. When I have created this individual this individual has a legitimate complaint to raise about her plight. I should have avoided creating her.

What are we to say of the merely possible (something I actually avoid doing) action of creating an individual with a miserable life, is it wrong (assessed from the point of view of the actual world where it is not performed)? I would say, no. It lacks normative status. Only actual acts are right or wrong, from the point of view here discussed. However, this prepares room for an argument against the view to which I return below.

We may speak of this general approach to morality as "actualist". Only actual individuals, who exist at one time or another, enter the moral calculus. Merely hypothetical individuals do not count.

Actualism allows that we put an end to humanity, but it does not require us to do so. However, to an actualist, the following argument has a strong appeal. We know that humanity will come to an end regardless of what we do (eventually the sun will turn into a white dwarf). Or I suspect that some (such as Toby Ord) think that we might someday "settle the stars". If so, the relevant cosmic endpoint needs not be the death of the sun, but of the galaxy or universe.

The last generation may come to face a hard time. However, whatever we do, there will be a last generation. The important thing, then, is to see to it that there will be a happy ending (as happy as possible) of humanity. When all is over, there is no one there who can voice any complaint. There is no moral point in reaching the end later rather than earlier.

This stance has been extremely popular among moral philosophers. One philosopher, in particular, who used this argument against my own utilitarian take on population ethics a long time ago was Georg Henrik von Wright, who claimed, for exactly the reason here mentioned, that it was a "pipa snus" (Finnish Swedish for a pipe of snuff, i.e., something of little or trifling importance) if the human race would go extinct. Post-festum, there would be no one left to lament the fact.

Finally, we meet with deep ecological thinkers arguing that what matters is that there is a variety and plurality of species. The individuals who make them up do not matter. Therefore, even if the number of humans is radically reduced, there may be compensation in the form of flowers, forests, and insects. The Norwegian philosopher Arne Naess, together with the American proponent of deep ecology George Sessons, have put the point thus:

The flourishing of human life and cultures is compatible with a substantial decrease of the human population. The flourishing of nonhuman life requires such a decrease. ${ }^{15}$

All these thinkers claiming that it does not matter whether human life continues on earth are wrong. It is of utmost importance that we carry on. The more of us the merrier, in the long run. Additionally, at present, we should strive for an optimal population. We should go to great length to achieve this goal. We should at each moment see to it that we are as many as possible without jeopardizing continuation of our collective presence into an indefinite future. 
This is my strong belief, but are there any good arguments in defence of it? What are we to say about the arguments in favour of indifference?

\section{Against Pessimism}

As to pessimism, it is tempting to argue that, had our lives in general been worth not living we would all have committed suicide long ago. This is how Epicurus famously argued:

Much worse is he who says that it were good not to be born, but when once one is born to pass with all speed through the gates of Hades. For if he truly believes this, why does he not depart from life? It were easy for him to do so, if once he were firmly convinced. If he speaks only in mockery, his words are foolishness, for those who hear believe him not. ${ }^{16}$

This is too simplistic, however. People may have all sorts of reasons for not committing suicide. Some find it morally objectionable for strict deontological reasons, regardless of the consequences. Others may argue from a consequentialist point of view, correctly, along the following lines. If I kill myself, this means that I need not live a life worth not living. However, my committing suicide may have negative consequences on others, in particular, on those close to me. Additionally, it is unlikely that they will follow suit. Therefore, I stay alive.

Another reason for going on with your life worth not living may be that you falsely believe that it is worth living or, you falsely believe that, at least in the future, it will become worth living. You conform to what has been called the Pollyanna principle. This is consistent with your life and your future being worth not living. Therefore, we need better arguments if we are likely to defeat pessimism. The following is the best we can do, I submit.

We have evolutionary reasons to believe that, typically, a human life contains a surplus of happiness over unhappiness. This fact sustains a desire go to on with one's life. It has survival value to be happy (on the whole). In particular, what makes you want to go on swimming is when you have your head just above the water. Not all the time, of course, and not all of us, but most of us for most of the time. There is a place as well for unhappiness in our lives, but that should be the exception, steering us away from dangerous lifestyles.

It might be objected that, also from an evolutionary point of view, it is sufficient for people wanting to go on with their lives that they believe they lead good lives. For all we know, we may live in bad faith. Falsely we believe that our lives are worth living but, in fact, they are not. Even a false belief in the value of one's life may create a will to continue with it, i.e., such a false belief may have survival value.

This is true. However, the easiest way of seeing to it that we believe that we lead, on the whole, most of us, most of the time, good lives, is by providing us with such lives, or, perhaps better put, to design us to respond with (moderate) happiness to our actual plight. Deception comes with an additional evolutionary price. All things equal, from an evolutionary point of view, it is in general better to have and depend on reliable methods of belief formation.

This is not to say that there is no room whatever for self-deception. It might very well be the case that people in general tend to hold an overly optimistic view about their

16 Epicurus, Letter to Menoeceus, OP: http://classics.mit.edu/Epicurus/menoec.html. 
own popularity among their peers or a much-too-optimistic view of some of their skills (for example, as drivers). However, these misconceptions, if they are real, ${ }^{17}$ tend to enhance their happiness rather than distort their perception of it. As a matter of fact, it is difficult to misperceive one's degree of happiness. Happiness is something we feel, and we feel what we feel, period. Therefore, at least momentarily, we are capable of keeping track of it. This is compatible, however, with the fact that in some special cases we go wrong when we try to recall entire parts of our lives. ${ }^{18}$ Hence, my main argument against pessimism is the evolutionary speculation, leaving some room for self-deception.

I have to admit, also, that my argument against pessimism depends on the assumption that prioritarianism is mistaken. If unhappiness carries a (much) heavier weight than happiness, then also a life with a net surplus of happiness may be worth not living. I have argued elsewhere that this implication counts against the view, and I have to leave it on that note in the present context. ${ }^{19}$

\section{Against Actualism}

As to actualism, we here meet with a line of thinking with strange implications. According to actualism, it would have been fine if God had not created Adam, Eve or any other sentient creatures, even if the creation contains a considerable surplus of happiness over unhappiness. This would have been fine even if what followed, then, was on the whole of positive value. This strikes me as wrong. However, this argument against actualism seems to presuppose what it is supposed to prove, so we should not rely too heavily on it.

Toby Ord, who has recently written about existential risks, is one of the rare authors in this field who does discuss actualism. This is how he comments on it:

... [the actualist argument] is no better than the old argument by the philosopher Epicurus that your death cannot be bad for you since you are not there to experience it. What this neglects it that if I step out into the traffic and die, my life as a whole will be shorter and thereby worse ... If a catastrophe this century were to cause our extinction, then humanity's life would be shorter and thereby worse. ${ }^{20}$

However, unless Ord adheres to a speciesist morality, claiming that it is of importance as such that members of the human species enjoys happiness, which I think would be an uncharitable interpretation of him, this argument also presupposes some total view.

Here, is a more promising line of argument. On actualism, it is morally acceptable to create a population with individuals living lives just worth living rather than another population, of the same size, with terrific lives. This strikes me as wrong. We meet here with a strong argument against actualism.

Finally, there are strange theoretical problems with actualism. Actualism does not satisfy a requirement of normative invariance. What we ought to do depends on what we actually do. Suppose I can create an unhappy individual, A. If in fact I do, I presumably harm this individual. This individual, we assume, leads a terrible life. Therefore, what I

17 There exists a vast literature on this, both confirming and questioning the phenomenon. There is no need to go into this in any detail in the present context.

18 Daniel Kahneman has given us many telling but also often exceptional examples of this, Daniel Kahneman, Thinking, Fast and Slow (New York: Ferrar, Straus, and Giroux, 2011), about this.

19 I develop this argument in Torbjörn Tännsjö, 'Utilitarianism or Prioritarianism,' ibid. I thank Jens Johansson for having stressed that I do operate with this assumption in the present context.

20 Toby Ord, The Precipice. Existential Risk and The Future of Humanity (New York: Hachette, 2020), 48. 
did was wrong. However, suppose my only option was to create another equally unhappy individual, B. Well, since, in fact, B does not exist, it was still wrong of me to create A. $B$ is a merely possible person who does not enter the moral actualist calculus. I should instead have created $B$, then.

However, suppose instead that, as a matter of fact, I do create B. Now this is wrong; instead, I should have created A. We suppose this is now my only alternative option.

This is no outright contradiction, but it does present a difficult paradox. ${ }^{21}$

\section{Against Deep Ecology}

As to deep ecology, it is mistaken. Species have no intrinsic value; what counts are experiences of happiness and pain among human (sentient) beings. Hence, we should not shame those who conceive children and blame global heating on their children. The people they put into existence, and the happy lives they lead, are indeed the very rationale for avoiding global heating. We should follow suit and create our own children. The globe can sustain a much bigger population, at least the 10 billion people we are heading towards-provided we take necessary environmental measures. The carbon must stay under the surface, it is as simple as that. If we cannot achieve that, we are already many too many on the globe.

However, if we want there to exist as many happy creatures as possible it is mandatory for us to keep going for as along a time as we can. If we are interested in the sum-total of happiness in the universe, as discussed below, and if I am right I am right in my insistence that, typically, we lead happy lives, but only moderately happy ones (we have our heads just above the water), then the time and number aspect of population ethics gain special importance. To garner a large sum of happiness in the universe, it takes many sentient beings and eons of time.

How can I be so sure that deep ecology is wrong?

It is tempting to argue that, metaphysically speaking, species are mere constructs, not natural kinds. Hence, they cannot be of value in themselves.

This argument is not convincing. The same may be true of individual human beings (persons or selves). Remember David Hume's dictum about the self as a mere "bundle of perceptions". ${ }^{22}$ Are selves not also mere constructs? Yet, according to some moral theories, such as ethical egoism, or ideas of distributive justice based on the notion of the separateness of persons, persons are of special moral importance.

The reasonable conclusion to draw from this observation is that we have reasons to believe in the objective existence of an entity, if it figures in an essential way in some of our explanations. This, of course, is reminiscent of Gilbert Harman, who in the opening chapter of his book The Nature of Morality, ${ }^{23}$ assumes that we have reasons to believe an entity exists if and only if we need to make a reference to it in the explanation of some of our observations. Here, "observations" are conceived of as events. We could generalize this principle to cover moral explanation as well. We should believe in the entities to which in our moral explanations of the content of our considered moral intuitions we make an

21 Derek Parfit in Reasons and Persons (Oxford University Press, 1984), 395, discusses an example of this kind and claims that it leads to contradiction, but this means that he overstates the (real) problem with the view. For a general discussion about it, see Krister Bykvist, 'Violations of normative invariance: Some thoughts on shifty oughts,' Theoria 73 (2007): 98-120.

22 David Hume, A Treatise of Human Nature, 1.4.6.4.

23 Gilbert Harman, The Nature of Morality. An Introduction to Ethics (New York: Oxford University Press, 1977). 
essential refence. I am furthermore prepared to argue that some of our moral observations (intuitions), conceived of as mental events, are best explained with reference to basic moral facts. ${ }^{24}$ Be that as it may, moral explanation should count in this credential test, I submit.

Why should we believe in Harman's recommendation about justified belief? Why believe in the generalised form I have here given to it? After all, it does not seem to live up to its own strict standard. We need not refer to it in any of our explanations of any observations or moral intuitions.

I assume that the best answer to this question is that, if we are interested in a realistic picture of the world, where we believe what is true and avoid believing what is false, we have good subjective reasons to abide by it. To adhere to it is to be rational in a straightforward means-to-an-end sense.

However, if moral explanations count, then the entities presupposed by deep ecology stand and fall together with deep ecology. If deep ecology is right in its claim that species are of value in themselves, then we have reasons to believe in the objective existence of species.

We cannot set deep ecology to one side by any simple metaphysical argument, then. If we want to reject it, we have to do this on moral grounds. Therefore, the question we must pose is, is deep ecology correct?

It is tempting to argue that, if I die prematurely, this is bad, since, had I not died (in the way I did), I would have had many happy years ahead of me (we may assume). However, if it also surfaces that I am the last specimen of my species, does this add sorrow to the fact that I extinguish? I deny that. This is not bad, as such. However, this is what is implied by deep ecology.

It is possible that, from an instrumental point of view, the fact that with me the human species goes extinct, does add sorrow. My species (the human species) may be of some special interest, instrumentally speaking. In that case, it is sad if it goes extinct. However, suppose its continued existence is of no interest for any instrumental reasons, suppose I am the last member of the human species which is to be replaced with a post-human species, more intelligent, happier, and smaller (requiring fewer material resources in order to lead a happy life), then, is it not all right that the species goes with me?

My strong intuition is that it is. What counts, in the final analysis, is happiness (and unhappiness), regardless of how it is instantiated.

\section{The Repugnant Conclusions}

Human extinction, without a better replacement, is a sad fact, however. This should be the common-sense view, one may think. Additionally, it is my view. The more (happy creatures) the merrier. However, this view is not only questioned by pessimists, actualists and deep ecologists of various kinds, it faces difficult theoretical problems in its own right. All "total" views, urging us to maximise the sum total of happiness in the world, in a straightforward manner (utilitarianism), or in a weighted sum, giving increasing weight to unhappiness and diminishing weight to happiness (prioritarianism), imply what Derek Parfit has nicknamed the "repugnant" conclusion: an enormous population of people leading lives just worth living is better than a population of ten billion extremely happy people. Thus, from this point of view, quantity trumps quality.

24 Torbjörn Tännsjö, From Reasons to Norms. On the Basic Question in Ethics (Dordrecht: Springer, 2010). 
However, is this really repugnant? I have over and over again argued that it is not. ${ }^{25}$ However, this view of mine still seems to be controversial. To see, in the present context, that it is not, think of it as a choice between the happy ending of humanity (ten billion happy individuals) as compared to an indefinite continuation of it (on a level where life is just worth living)? My intuition is that we should opt for continuation, even at the cost of average happiness, as long as the sum total increases. ${ }^{26}$

Some people disagree with the repugnant conclusion, however. However, is it possible to reject the repugnant conclusion without ending up in the thought that it does not matter if humanity goes extinct? This has proved extremely difficult (I would say, impossible).

It might be tempting to suggest that we should opt for the world with the best average of happiness. Derek Parfit has shown why this is not a viable option. It means that we should add people with terrible lives to a world where everyone leads an even more terrible life, in order to lower the average unhappiness. This is absurd. ${ }^{27}$

Should we claim that there exists a critical level of happiness, say at +7 , under which our lives are of negative moral value, or of no value at all, even though they are subjectively speaking worth living (above 0)?

No, if we claim that a life at +6 is of negative moral value it means that we may have to torture one individual in order to avoid many additional lives at +6 . This conclusion, by Gustaf Arrhenius called "sadistic", is again absurd. ${ }^{28}$ Additionally, even the idea that a life between 0 and +7 is of no moral value is problematic. It means that we must be indifferent between a world with ten billion people at +1 and a world with ten billion people at +6 . However, the latter world is clearly better than the former one.

Could one focus on possibilities lost, of we humans go extinct, without presupposing any total view? This is suggested by Toby Ord in the following words:

The challenge of our time is to preserve our vast potential, and to protect it against the risk of future destruction. The ultimate purpose is to allow our descendants to fulfill our potential, realizing one of the best possible futures open to us. ${ }^{29}$

25 For example, in Torbjörn Tännsjö, 'Who are the Beneficiaries?' Bioethics 6 (1992): 288-96; Torbjörn Tännsjö, 'Why We Ought to Accept the Repugnant Conclusion,' Utilitas 14 (2002): 339-59; Torbjörn Tännsjö, 'Why Derek Parfit Had Reasons to Accept the Repugnant Conclusion' Utilitas 32 (2020): 387-97; OA: www.cambridge.org/core/services/aop-cambridge-core/content/view/ AB0C0590403FE9519FF76EF5A6A2426B/S0953820820000102a.pdf/why_derek_parfit_had_reasons to accept the repugnant_conclusion.pdf, and most recently in Zuber, S., Venkatesh, $\overline{\mathrm{N}}$., Tännsjö, T., Tarsney, C., Stefánsson, H., Steele, K., . . . Asheim, G. (2021). What Should We Agree on about the Repugnant Conclusion? Utilitas, 1-5. doi:10.1017/S095382082100011X. For a general introduction to the discussion on this topic, see Gustaf Arrhenius, Jesper Ryberg and myself, 'The Repugnant Conclusion,' Stanford Encyclopedia of Philosophy, https://plato.stanford.edu/entries/repugnant-conclusion/.

26 There are many ways of "debunking" the intuition that the repugnant conclusion is repugnant, but I cannot go into all of them here. It might also be that some agree with me about the example here given for the wrong reason. They feel that it is of importance as such that the world is populated, regardless of the quality of the lives lived. In the final analysis, we should not rely on our intuitions about the conclusion, but consider the strong arguments that count in favor of its truth. This is beyond the scope of the present article.

27 Derek Parfit, Reasons and Persons, ibid., p. 422.

28 Gustaf Arrhenius, 'An Impossibility Theorem for Welfarist Axiology,' Economics and Philosophy 16 (2000): 247-66.

29 Toby Ord, The Precipice. Existential Risk and The Future of Humanity (New York: Hachette, 2020), 38. 
However, this is not a plausible view. Certainly, what should count, morally speaking, if we go extinct, is not what could have happened, had we stayed around, but what would have happened.

The theoretical problem of avoiding the repugnant conclusion without dropping into the view that it does not matter if humanity goes extinct has proved to be equal in difficulty to the practical problem of how to avoid global heating. ${ }^{30}$ However, there is a simple theoretical way out of this dilemma: to accept some total theory-it need not be total utilitarianism, ${ }^{31}$ but that is in my opinion the best shot-implying the repugnant conclusion. Upon closer inspection, this seems to be a reasonable - the only reasonable-intellectual move to make in population ethics. If we make this theoretical move, we may also face the practical climate crisis in a responsible manner.

\section{Life Boat Ethics}

It is important that humanity is saved from the threat posed by global heating. The pessimists, the actualists, and the deep ecologists make moral mistakes in their reasoning. When we discuss existential risks in general and the risk posed by global heating in particular, we should rely on some total moral view. However, the threat from global heating will not be averted through negotiations between nation states. The tragedy of the commons stands in the way of such a solution. It will not be solved by one rich state such as the USA buying and closing down all fossil industries in the world. The US would not get away with the controls and sanction systems that such a solution would require. It will not be solved by the establishment of a global democracy. Time is too short for that. The threat may be obviated through global despotism, of some sort, however. In this I have put, and do put, my hope. The hope, however, is feeble. Many people dislike the idea of a world state as such, and even more so of a global despotism, and this scepticism may be the factor that renders the project impossible to realise. Does this mean that we are likely to go extinct when the globe is heated up? There may be one more way out of our plight. This is a nasty one but still one better than total extinction. We may speak of it as a situation of life boat ethics. Here, Garrett Hardin, who invented the term "the tragedy of the commons", enters the picture once again. Now with another metaphor: "Life boat ethics". ${ }^{32}$

Garrett Hardin became infamous when he introduced the term "life boat ethics" and when, based on incorrect Neu-Malthusian speculation about population growth, he concluded that rich countries should be complacent when famine strikes poor parts of the globe. In the present context, however, his idea makes perfectly good sense.

Suppose that after the COVID-19 pandemic we return to business as usual. There are many attempts to embark upon a green deal, but by and large, we continue with substantial greenhouse emissions. The effects soon become visible. Some nations disappear under the water. Many climate refugees begin to walk the globe. Soon, we realise that we have passed important tipping points. There is nothing we can do any more to obviate disaster. Nation after nation disappears; the rest close their borders. We happen to live in one, perhaps the only surviving one. Our nation has been turned

30 Gustaf Arrhenius seminal forthcoming book, Population Ethics: The Challenge of Future Generations (Oxford: Oxford University Press), bears witness to this.

31 See Torbjörn Tännsjö, 'Why Derek Parfit Had Reasons to Accept the Repugnant Conclusion,' ibid.

32 Put forward in Garrett Hardin 'Lifeboat ethics: The case against helping the poor,' Psychology Today 8 (1974): 38-43, and Garrett Hardin 'Living on a lifeboat,' BioScience 10 (1974): 561-8. 
into a gated community. When refugees knock on our door, we ignore them. For simple egoistic reasons, we keep our doors closed. We realise that, if we let them in, then we will only go under together.

This is sound egoistic reasoning. Can also a moral rationale be found behind it? Perhaps it can. It can if correctly we conclude that, if we stay in our gated community and do all we can to sustain life for an indefinite future, then there will be a continuation of our species.

We learn much in these days about travels to distant planets in order have humanity survive on one of them. ${ }^{33}$ It would probably be easier to keep some part of our own planet habitable. Therefore, assume that this is what we do. Some of us survive, they keep humanity going, and there comes a time when it is possible for human beings to make the planet as such habitable again. Then, time for a human renaissance has come.

Would this way of acting be morally permissible? From the point of view of some total view, it would. We should remind ourselves here of Derek Parfit's thought experiment:

I believe that if we destroy humankind, as we now can, this outcome will be much worse than most people think. Compare three outcomes:

(1) Peace.

(2) A nuclear war that kills $99 \%$ of the world's existing population.

(3) A nuclear war that kills $100 \%$.

(2) would be worse than (1), and (3) would be worse than (2). Which is the greater of these two differences? Most people believe that the greater difference is between (1) and (2). I believe that the difference between (2) and (3) is very much greater.... The Earth will remain habitable for at least another billion years. Civilization began only a few thousand years ago. If we do not destroy humankind, these few thousand years may be only a tiny fraction of the whole of civilized human history. The difference between (2) and (3) may thus be the difference between this tiny fraction and all of the rest of this history. If we compare this possible history to a day, what has occurred so far is only a fraction of a second. ${ }^{34}$

Parfit does not provide any moral rationale behind his intuitive moral reasoning. The reasoning is sound, however, and it can be given a solid rationale. What is needed is a total view, preferably a total utilitarian one. Additionally, it is perfectly clear that this argument can be generalized to the situation of the last gated community on earth.

\section{Conclusions}

A growing suspicion must be that behind the political inaction in relation to global heating lurks the idea that it does not really matter if we go extinct. Many popular arguments, from pessimism, actualism, and deep ecology point in that direction. Additionally, the defence of optimism and the idea that also merely possible individuals count in the correct moral calculus is fraught with theoretical difficulties. In particular, if the only way to avoid global heating and human extinction is global despotism, some seem to say, "Who Cares?"

33 It is of note that the ambition to colonialize other parts of our solar system has been considered in itself to pose an existential threat to humanity. See Daniel Deudney, Dark Skies (Oxford: Oxford University Press, 2020) for (a spectacular) argument to this effect.

34 Derek Parfit, Reasons and Persons (Oxford: Clarendon Press, 1984), 453. 
Well, I do, and the main thrust of the argument of this paper is that we should all go to great length, and, if necessary, endure much present hardships such as an enlightened global despotism, and even a policy of life boat ethics, in order to save for as long time as possible the existence of an optimal population of happy sentient creatures on the globe.

This practical conclusion is founded on a theoretically acceptance of some total theory in population ethics, such as utilitarianism, implying the repugnant conclusion. 